\title{
Recueil général de moralités d'expression française, éds. Jonathan Beck, Estelle Doudet et Alan Hindley
}

\section{G. Matteo Roccati}

\section{(2) OpenEdition}

1 Journals

\section{Édition électronique}

URL : http://journals.openedition.org/studifrancesi/4319

DOI : 10.4000/studifrancesi.4319

ISSN : 2427-5856

Éditeur

Rosenberg \& Sellier

\section{Édition imprimée}

Date de publication : 1 septembre 2016

Pagination : 311

ISSN : 0039-2944

\section{Référence électronique}

G. Matteo Roccati, «Recueil général de moralités d'expression française, éds. Jonathan Beck, Estelle Doudet et Alan Hindley », Studi Francesi [En ligne], 179 (LX | II) | 2016, mis en ligne le 01 septembre 2016, consulté le 18 septembre 2020. URL : http://journals.openedition.org/studifrancesi/4319; DOI : https://doi.org/10.4000/studifrancesi.4319

Ce document a été généré automatiquement le 18 septembre 2020.

\section{(c) $(1) \ominus$}

Studi Francesi è distribuita con Licenza Creative Commons Attribuzione - Non commerciale - Non opere derivate 4.0 Internazionale. 


\title{
Recueil général de moralités d'expression française, éds. Jonathan Beck, Estelle Doudet et Alan Hindley
}

\author{
G. Matteo Roccati
}

\section{RÉFÉRENCE}

Recueil général de moralités d'expression française, sous la direction de Jonathan $\mathrm{BECK}$, Estelle DOUDET et Alan HINDLEY, Tome III, La Moralité de Bien avisé Mal Avisé, Édition critique par Jonathan BECK, Paris, Classiques Garnier, 2014, «Bibliothèque du théâtre français» $21,342 \mathrm{pp}$.

1 Après le tome I (voir Rassegna, t. LVIII, n. 173, p. 341), parait maintenant le t. III du Recueil (le t. II n'a pas encore paru) contenant une des moralités les plus connues, conservée dans deux versions différentes dans un manuscrit (BnF, Rothschild 2797) et dans un imprimé de Vérard (dont on connaît quatre exemplaires; reproduction photographique: Helmich, 1980). Le texte a été établi d'après le manuscrit unique, avec des intégrations à partir de l'imprimé de Vérard («bon nombre de vers sautés dans le manuscrit», p. 23, rétablis d'après la reproduction photographique). «Les deux versions sont sensiblement différentes, aussi bien au niveau du détail qu'en ce qui concerne la cohérence de l'ensemble» (pp.16-17), la version de l'imprimé «dont le texte a très souvent souffert d'erreurs de lecture - et donc de copie - ainsi que de remaniements inconsidérés ou simplement ineptes» a été utilisée seulement pour contrôle «lorsque cela a été possible et utile» (p.15). L'introduction (pp. 9-43) présente le texte et sa langue; l'édition, accompagnée de notes, est suivie de la liste des corrections apportées (exceptées les corrections de routine), du glossaire (pp. 319-334), de la bibliographie et de l'Index des proverbes et des locutions proverbiales.

2 Le volume rend service pour prendre connaissance du contenu du texte et surtout pour prendre la mesure de l'autonomie de la version manuscrite (voir notamment l'Analyse 
de la pièce par épisodes, dans les deux versions, pp.17-21). On regrette toutefois que l'édition n'ait pas vraiment pris en compte cet aspect. En réalité nous sommes en présence d'une version «narrative» de la pièce dramatique. L'homogénéité du manuscrit (cf. pp. 15-16) le suggère: la mise en page - décoration de la page de titre, rubriques et illustrations - est très proche de celle des deux œuvres qui précèdent la moralité: Le pas de la mort d'Amé de Montgesoie et Le chevalier délibéré d'Olivier de la Marche, deux récits strophiques au contenu moral et allégorique. La présentation de la copie le confirme et révèle le travail de réécriture auquel le texte a été soumis: des didascalies narratives ont été ajoutées, l'encre rouge est utilisée pour les rubriques avec le nom des personnages et, au moins partiellement, pour les citations bibliques, aucune note renvoyant à la mise en scène, aucun signe habituel dans les «manuscrits de théâtre», comme les crochets alinéaires, n'apparait. On aimerait comprendre mieux le travail du copiste, certes fautif, mais surtout tout à fait «interventionniste»: «dans de nombreux vers [il] a changé l'ordre des mots en sacrifiant la rime, en faveur d'un tour syntaxique qui lui semblait préférable à ce qu'il trouvait dans le texte qu'il copiait» (p. 300); dans la foulée de l'écriture il invente même un personnage, créé sans réfléchir à partir d'un souvenir du Chevalier délibéré (p. 180). Aussi, l'absence presque totale de formes «fixes» est curieuse dans une moralité, on se demande si elles n'ont pas été tout simplement «résorbées» dans le texte copié: on trouve parfois des "vers répétés par inadvertance» (p. 23), quand ils sont simplement répétés entre la fin d'un feuillet et le début d'un autre la faute de copie parait certaine, mais ailleurs (cf. p. 98, 184)? À côté des erreurs d'inattention, ils pourraient témoigner, de même que les repentirs, du travail de réécriture, parfois inachevé ou bâclé. 